\title{
A Model of Translation of Politeness Based on Relevance Theory
}

\author{
Fang Wang \\ College of Foreign Languages, Changchun University of Science and Technology, Changchun, China \\ Email: harmonywang@163.com
}

Received 6 July 2014; revised 24 August 2014; accepted 9 September 2014

Copyright (C) 2014 by author and Scientific Research Publishing Inc.

This work is licensed under the Creative Commons Attribution International License (CC BY). http://creativecommons.org/licenses/by/4.0/

c) (i) Open Access

\begin{abstract}
Sperber and Wilson developed the Relevance Theory of communication. It did not take long before it was applied to translation. This dissertation attempts to illustrate the model of the translation of politeness. Translation is a cross-linguistic sociocultural practice, in which a text in one language is replaced by a text with equivalent relevance degree in another. The original contains three variables, which, once summed, give the weightiness of the face-threatening act and the choice of stimulus is decided.
\end{abstract}

\section{Keywords}

Relevance, Politeness, Relevance Degree, Translation

\section{Introduction}

Since the 1950s [1], serious studies of translation have reached a climax. Among the many approaches to research on translation that are producing useful perception nowadays, pragmatic approaches have been in particular favor. The Relevance Theory of communication was developed by Sperber and Wilson in the mid 1980s [2]. It was soon applied to translation [3] [4]. It is mainly concerned by those who are interested with a cause-effect understanding of translation as an act of communication: if the human mind goes about communication in translation, what will be the likely effects of particular solutions, or what solutions are needed to achieve particular effects? The whole scientific field within which these explanations are searched for is cognition [3].

Since the idea of linguistic politeness was led to the stage center of the politeness model raised by Brown and Levinson [5] [6], the concepts of the model have been discussed in vast following literature which has focused on linguistic carriers of politeness, in order to measure them, to compare them across genders and cultures, and to shed light on the world which we live in.

Then how can one make sure in translation that politeness contained in the original is "carried over" in the 
translation? How can one reach "politeness equivalence" in translation? If there is a theory of politeness in which both the universal points of view and cross-cultural differences in the realization of politeness can be accounted for, it must be a broad and general one, which is supposed to cover the concepts of politeness regarded relevant for translation and attain optimal relevance, as suggested by Gutt [3].

House explores the relationship between translation and politeness [7]. She distinguishes the concepts of covert translation and overt translation. And she also employs a "cultural filter" model of translation, which she allows for differences in social norms and differences in politeness norms. One weakness of this analysis is that translations that focus on the preservation of linguistic features of the original does not fit under the notion of interpretive use, though they can be accommodated as resemblance-based cases of ostensive-inferential communication in a more general sense [3] [8].

Another is that her distinction between "covert" and "overt" mode seems to be based on an idealization, the notion of complete interpretive resemblance that can in practice rarely be achieved, esp. not in the case of translation. This article seeks to explore the relationship between translation and politeness. A number of recent conceptualizations will be critically reviewed. Secondly, the issue of cross-cultural differences in politeness norms will be discussed; it will be concentrated on the description and explanation of differences in Chinese-English norms as they have emerged from contrastive linguistics. Thirdly, the Relevance Theory observations on politeness and translation will be introduced.

\section{An Overview of Politeness}

\subsection{Definition of Politeness}

Politeness is a sociocultural phenomenon, roughly to be defined as showing, consideration of others [7]. Politeness can thus be considered to be one of the basic social concepts in human communication. The goal of politeness can then be described as reflecting or realizing the social or interpersonal function of language with politeness being "a system of interpersonal relations designed to facilitate interaction by minimizing the potential for conflict and confrontation inherent in all human interchange” [9]. While politeness concerns human communicative behavior in general, this dissertation will only be concerned with linguistic behavior.

\subsection{Perspectives on Politeness}

For many researchers, politeness is a feature of language in use. Thus Brown and Levinson [6] and Leech [10] stress the importance of politeness as a conceptualized phenomenon. Further, it is generally accepted that politeness is a deep-rooted feature in human communication. Despite the recognized importance and popularization of politeness in daily discourse, it has proved enormously difficult to describe and explain the operation of politeness. As Thomas [11] points out, there has been a lot of confusion in the vast literature on politeness over the past 15 years or so, and it has been discussed with reference to a number of phenomena that can be kept separate conceptually, such as (1) politeness as a real-world goal, (2) politeness as reflecting social norms and (3) politeness as a pragmatic phenomenon. Each of these will be discussed in turn.

\subsubsection{The Real World Goal Perspective}

As a "real-world goal", politeness is psychologically taken as the genuine desire to be good to others. It relates to the addresser's personal motivation and psychological state. It is considered inaccessible to linguists who can only access to what addressers say. So it is considered to be of no relevance to translation theory and practice [7]. This will be reexamined in the article.

\subsubsection{The Social Norm Perspective}

Politeness requires people to show how they think of others or to show that they don't think more highly of themselves than they should. In Chinese, for instance, this may require someone to show that one respects the social status of others or that one does not admire one's own social position extensively. But in English, it may require to show that one respects the power of others has nothing to do with imposition, neither one thinks too highly of one's own right.

What forms showing that one thinks better of others or at very least showing that one does not think evilly of others, and showing that one does not think more highly of oneself than one should do, involves a number of 
aspects that vary from culture to culture. That is to say, politeness is a phenomenon which is sensitive to cultures.

In the light of communication which reveal an addresser thinks well of others or at least not evilly of others, addressees perceive how others think of them. Addressees perceive how others think of themselves, based on utterances which show that an addresser does not think more highly of himself than he should. As the addressees perceive the utterances appropriate as demanded by social norms, all kinds of types of politeness come up. These social norms change according to different situations and different persons. That is to say, politeness is subtle to situation, and perceptions of it vary across native addressers of a language.

Fraser holds: "The social norm view of politeness assumes that each society has a particular set of social norms consisting of more or less explicit rules that prescribe a certain behavior, a state of affairs, or a way of thinking in a context" [12]. According to Nwoye [13], within the social norm view politeness is "seen as arising from an awareness of one's social obligations to the other members of the group to which one owes primary allegiance". On the other hand impoliteness comes up as one's behaviors are contrary to the norms in the given society.

\subsubsection{The Pragmatic Perspective}

There are three major pragmatic perspectives of politeness.

\section{1) The Conversational-Maxim Perspective}

The conversational-maxim view of politeness depends mainly on the theory of Grice [14]. He holds "conversationalists are rational individuals who are, all other things being equal, primarily interested in the efficient conveying of messages" [12]. Then, Grice [14] argues that the most important rule in conversation is the cooperative principle (CP), that is, to "make your conversational contribution, for example, is required, at the stage at which it happens, by the accepted purpose or direction of the talk exchange which you are engaged in".

\section{2) The Conversational-Contract Perspective}

According to the conversational-contract perspective, when starting a dialogue, each part "holds an understanding of some initial rights and obligations that will determine, at least for beginning stages, what the participants can expect from the other(s)" [12]. These rights and obligations are on the basis of the parties' social relationships with one another and can be altered during the process just as an ambiguity between the lines. This forms the conversational contract (CC). Therefore, from this perspective, politeness has the meaning of working within the terms and conditions of the being CC. If one breaks the rule of CC, then one is regarded as an impolite person. This perspective is close to the social norm perspective. Nevertheless, these two perspective $s$ are not same in that in the CC perspective, the rights and obligations of parties can be different.

\section{3) The Brown and Levinson Face-Saving Perspective}

Brown and Levinson construct a Model Person (MP) to account for language usage. Their MP is a fluent addresser of a language who has two special properties rationality and face. By "rationality" Brown and Levinson mean that the MP would be able to use a specific mode of reasoning to choose means that will achieve his purposes. Brown and Levinson [6] define "face" as the "public self image that every member wants to claim for himself". For the MP this means that he is supplied with two particular wants that he will try to maintain in interactions with others. Brown and Levinson entitle these two as positive face (the desire to be accepted and have what one wants approved by others) and negative face (the desire for independence, not to be imposed on by others). While Brown and Levinson [6] hold universal perspectives of politeness and argue that individuals are interested in maintaining the face of others in the interaction so that others will do the same to them, like Lakoff [15] they also hold that within a certain culture, the content of face is specific. In other words, what is considered linguistically polite behavior in one community may not necessarily be regarded as polite in another. And communities may differ in their preferences i.e. some may show preference for negative politeness while others may have a positive politeness culture.

Brown and Levinson hold that the addresser adopts face-saving strategies in order to be politer. Such strategies permit one to break Grice's CP. For instance, the statement "Close the window" is agreeable in Grice's CP, but might be considered impolite by the addressee with the view of Brown and Levinson's face-saving perspective. This perspective is based on the view that politeness "consists of a special way of treating people, saying and doing things in such a way as to take into account the other person's feelings" [16]. As a result, if a person would like to show politeness, his speech would be more complicated and indirect. According to Brown and Levinson's model, although when communicating with one another people generally co-operate with each other in order to maintain face, there are certain acts which are doomed face-threatening acts (FTAs), e.g. requests or 
warnings. When confronted with FTAs people would choose speech strategies to reduce or dispose of such threats, for example, by softening a request or warning, or by expressing themselves indirectly. In such cases addressers would evaluate the level of the threat, considering factors such as the degree of power that communicators have over each other, the social distance and the imposition existing in a given speech act, before choosing an appropriate strategy. The definition of "face" proposed by Brown and Levinson describes face as an image that intrinsically belongs to the individual, to the "self" [17], i.e. a "private face". This is different from Goffman's [18] perspective, who takes face as a "public property" that is only given to individuals relying upon their communication [17]. From Mao's [17] perspective, "Goffman's face is a public, interpersonal image, while Brown and Levinson's face is an individualistic, "self-oriented image". Brown and Levinson's claim that the notion of positive and negative face is universal is really a strong statement. It is important to note that recent non-Western research of politeness has disproved Brown and Levinson's claim of the universality of the concepts of positive and negative face. Particularly, Brown and Levinson's model does not appear to be able to deal with discourse behaviors in non-Western cultures where the primary communication core is not on individualism but on group identity [19] or where politeness signals different moral meanings or normative values [13].

\subsection{Cross-Cultural Differences in Politeness}

\subsubsection{Cross-Cultural Differences in Politeness as Social Norms}

Early cross-cultural studies were conducted, e.g., by Fraser [20], as well as by House and Kasper [21]. In these studies, the realization of certain speech acts as well as the understanding of politeness by native-addressers and learners of particular languages (English and Spanish or English and German) are compared and connected with fundamental societal norms of usage.

Later studies include data-based cross-cultural investigations of the impact of isolated social and context factors on norms of politeness. Thus "Social Distance" is examined and found to influence politeness in the realization of speech acts in a complex way. "Social Power" which consists of different cultural and situational factors is also investigated.

Except these cross-cultural investigations of the influence of social variables on politeness, specific features of speech acts such as "the imposition" sustained through the act have been contrasted, e.g. requests, apologies and complaints.

The complex interaction of the various contextual and participant variables has also been contrasted with reference to the realization of requests. Moving away from isolating contextual variables, researchers have increasingly concentrated on exploring the constitutions of politeness in different communication environments, such as everyday face-to-face interpersonal talk or communication in workplace.

Vast criticism has recently been directed at the universal claims of politeness inside the cross-cultural pattern, e.g. by Ide et al. [22], who contrasted Japanese and English politeness norms declaring that there is a necessary choice of "formal" linguistic forms and "discernment" in some non-Western languages, forcing addresser to use "polite" expression because of certain social customs. This is very different from the British freedom.

\subsubsection{Cross-Cultural Differences in Politeness According to Maxims and Principles}

The maxim-and-principle perspective of politeness is supposed to be useful to explain cross-cultural differences in the constitutions of politeness. Thomas [11] gives a number of examples of the realizations of Leech's politeness maxims in specific culture. The Tact Maxim, for instance, seems to be very important to Western notions of politeness since the Westerners tend to soften certain speech acts such as requests by offering option. The Chinese conception of politeness is a different case. Further, the Agreement Maxim, which is related to "indirectness" in speech act and discourse behavior, is supposed to be able to explain the differences in indirectness and politeness. However, the relationship between indirectness and politeness was found to be more complicated than had been predicted by politeness models, while conventionally indirect requests, such as could you, is considered more polite, non-conventionally indirect requests i.e. hints, although clearly much more indirect, are considered less polite, maybe because of the addressee's high processing effort.

In order to illustrate both cross-culturally different social norms and negotiable realizations of maxims and principles, and to provide a better basis for linking translation and politeness later, some samples are briefly summarized here:

1) Directness vs. indirectness: Chinese are found to prefer more direct expressions. 
He shows difficulty in distinguishing between imaginary and factual material.

2) Explicitness vs. implicitness: Chinese tends to be more explicit. I know better.

3) Self-referencing vs. others-referencing: Chinese is more self-oriented. You have my apologies.

4) Addressee-approbation and self-modesty of Chinese: Your school, I.

Given these cross-cultural differences in social norms that reflect politeness standards, one can hypothesize that the Gricean Maxims of Quantity and Relation tend to be interpreted differently in Chinese and English. Within the frame of reference provided by Lakoff [9] [15], it seems that all three principles of politeness are explained in Chinese and British cultures: the principle of politeness "Don't impose" is taken different meanings in Chinese because of a preference for higher directness levels in the realization of certain speech acts. The Rule "Give options" is also explained due to a preference for higher directness levels and explicitness of content in Chinese. The rule "Be hospital" in particular is interpreted and realized differently in the Chinese culture which prefer explicated content over addressees, sell-referencing overother-referencing, reduced reliance on conversational routines and greater directness in speech-act realization to a preference for higher directness levels and explicitness of content in Chinese. The rule "Be friendly" in particular is interpreted and realized differently in the Chinese culture which prefers explicated content over addressees, sell-referencing over other-referencing, reduced reliance on conversational routines and greater directness in speech-act realization.

\section{Relevance and Politeness}

\subsection{Relevance and Communication}

Sperber and Wilson [23] base their inferential model of communication on Grice's analysis of the notion of utterance meaning. Grice claims that as an individual modifies the behavior-verbal or otherwise- to communicate, he has two aims at least: the aim that his behavior has some effect and the aim that the former one can be identified. Sperber and Wilson term the first of these the informative aim and the second the communicative aim. Obviously, one can tell others something without that person's awareness of one's of intention to do this, but according to the Sperber and Wilson's definition this is not communication. One can unconsciously reveal one's informative intention and this, according to Sperber and Wilson, is a case of (accidental) communication.

Sperber and Wilson differ from Grice in the thing which guides the interpretation of intention. Grice suggested that communicators follow a number of norms when engaging in communicative behavior and that a tacit agreement leads the addressee to the intended interpretation. He based these norms on considerations of truth, relevance, clarity and informativeness. In contrast, Sperber and Wilson argue that what guides the interpretation of communicative behavior is not the observation of a set of conventions, but the way human central cognitive systems have developed.

\subsection{Politeness and Communication}

Since the outline of communication has been discussed, the question of what is communicated by linguistic politeness can be dealt with. As noted in the introduction, Brown and Levinson [6] are definitely sure that what is communicated is politeness:

"Politeness is then a major source of deviation from rational efficiency, and it is communicated precisely by that deviation." [6]

For the relevance theorist, this position causes some questions: How does the communication of politeness influence the mutual cognitive environment? What is the real meaning of the text? And does this indicate that politeness is usually uttered, as Brown and Levinson suggest? Or is politeness communicated only in particular cases, and if so then how can these be recognized?

There are two "messages" that politeness could surely convey, and communication of the first is a precondition for the second. According to Brown and Levinson's model the choice of strategy depends on three variables: the power advantage $( \pm \mathrm{P})$, if any, that the addressee has over the addresser; the social distance that exists between the addresser and addressee $( \pm \mathrm{D})$; and the ranking of that imposition in the culture concerned $(\mathrm{Rx})$. Totally, these three factors constitute the weightiness $(\mathrm{Wx})$ of the face-threatening act and a linguistic form/pragmatic strategy is chosen that can reflect this. However, the relation between strategy and the weightiness of a face threatening act (FTA) is the key to the first message that politeness might communicate. P, D and Rx are socially determined values and one would expect them to be mutually manifest to participants in a communica- 
tion. However, if one party involved in communication should employ a strategy which does not fulfill these expectations, the result will be a change in the addressee's cognitive environment. Moreover, a form or strategy of this type would be highly relevant to the addressee as it would be the evidence that the addresser ranked one of the three variables in a manner incompatible with the addressee's assumptions about their mutual cognitive environment. And being thus relevant, it would encourage the addressee to infer which variable he had misranked, which causes his reassessing the variable whose ranking was not strongly manifest to him [6]. Even though, the only change is to the addressee's cognitive environment and there will be no communication.

\subsection{Relevance Theory Observations on Politeness}

As illustrated in the previous section, it is obviously hard to hold that the reason for engaging in what is generally called polite behavior is to communicate politeness. It has been discussed that politeness is only recognized-when some aspect of the addresser's behavior provides evidence for the addressee that the addresser holds addressee in higher or lower position than the latter had assumed. From this perspective, many examples of what a linguist could define instances of polite behavior even might not be noticed by the communicators. One aim of this section is to show that there is indeed an acceptable substitute.

To find out why different linguistic forms and pragmatic strategies are applied to perform the same speech acts, it is of necessity to reconsider the process of utterance explanation. From the related theoretical view, utterance interpretation can be taken as primarily a process of selection rather than one of decoding though decoding is, of course, involved.

Of course, this will be confined by the need to use an optimally relevant stimulus, one which guides the addressee to the intended interpretation without any unnecessary processing effort. Nevertheless, there are further restrictions. Communicators have their different purposes which can be short or long term. In the short term , a person's purpose will be direct that he will try to convince the other one of something; while, in the longer term, his aims may involve to merge himself into a desired group and accepted by the group members. Based on that illustration, it is obvious that communicators will be confined by the strong will to fulfill the aims. Meanwhile, a speaker will plan to choose a stimulus to the achievement either his long or short term aims.

Surly, simply providing the proof that you hold may not necessarily lead to an understanding of agreement. On one hand, the fact you represent must be closed relevant, be worthy of the hearer's attention and trust according to his social knowledge. You must hold your evidence in higher position than he had assumed to be. On the other hand, it must be sincere; that is to say, the addressee must believe that the evidence you offer actually reflects the position in which you hold him. He must not think that your behavior is motivated by an attempt to raise, however indirectly, your own standing in his eyes by insincerely indicating that you hold him in higher position than is in fact the case. Thus similar understanding may start beneficially in one context.

To conclude, addressers, when they choose linguistic strategy, are likely to offer evidence as to the position where they hold the addressee. Addressers with the purpose to achieve their aims long or short term will select strategies that they believe will offer facts that the addressee's evaluation of the position, which is equal to the unidentified social coding view of politeness. Or, addressers may choose a strategy that will constitute evidence that he holds the addressee from a higher position than the latter had assumed. As far as repair is concerned, the addresser will be joyful to be obvious to the addressee for his aim.

Thus we can see that the relevance theoretic view emphasizes how addressers manipulate their utterances in a particular method to find out contextual characteristics with the purpose of forming their addressees' cognitive environments. When it is used to linguistic politeness, it is able to adjust the argument and observations of many linguists. But most importantly, it provides a substitute to the view that polite verbal behavior is motivated by the desire to communicate politeness. As such, the view of politeness suggested by Relevance Theory is to be preferred to that offered by norm-based accounts.

\section{Relevance-Theory Observations on Translation}

\subsection{Basic Foundations of Relevance Theory}

Since this study is based on the relevance-theory, it is necessary to introduce a few essential concepts of it here.

\subsubsection{Context}

In Relevance Theory, the concept of “context of an utterance” is “a psychological notion, the addressee’s as- 
sumptions about the world", more specifically, it is "the set of premises used in interpreting utterance" [23]. Within that definition, "context" is a very wide conception that can actually include any phenomenon in human mind:

Note that this notion of context also includes the text surrounding an utterance, what has sometimes been called the "co-text".

A second significant feature of context is that it is taken to be organized, and that this organization influences the accessibility of a certain piece of contextual information on a certain situation. For example, having just talked about childhood memories, information about some of your toys may be very easily accessible. On another occasion, though, it might take considerable effort to remember the color of your first big toy. Thus there is a relation between the accessibility of information in our minds and the effort required to recall it. With this clarification about context we now return to the question of how it is possible for addressees to find and use the contextual information which the addresser intended them to use and which is necessary for understanding him correctly.

\subsubsection{Optimal Relevance}

According to Sperber and Wilson [23], the main factor that makes communication succeed is both the communicator and the addressee's achieving of optimal relevance. An utterance is most related to the topic when it makes the audience find the meaning with only necessary effort indicated by the communicator and as that indicated meaning deserves the audience's attention, it offers enough goods to the audience. These benefits are psychological in nature; they consist in modifications of a person's knowledge and are referred to as "positive contextual effects". The function of optimal relevance in communication is the principle of relevance, which is believed to be an inherent constraint in our human psychological character. Based on the rule, no matter when an individual starts to communicate with somebody, he will communicate the presumption that what he is going to say what is believed to be best related to the topic shared with his audience.

This claim guides the addressee in capturing the addresser-intended context for a given utterance to optimal relevance in the following way. It makes him expect that the contextual information needed for the correct interpretation is readily accessible. So he begins the interpretation process from information most readily available to him at that time. Furthermore, he will assume that, when combined with the right context, the utterance will yield an interpretation that is worth the effort.

On these assumptions, the addressee will proceed with the interpretation process until he arrives at an interpretation that measures up to both conditions: it is derivable without unnecessary effort and yields adequate contextual effects. That is to say, the request to optimal relevance guides the addressee to accept the first interpretation consistent with the principle of relevance as the addresser-intended interpretation. Thus, the search for optimal relevance guides the addressee not only to the addresser-intended context but also to the addresser-intended understanding. It ought to be added here that people sometime are insensitive to these interpretation procedures in their thoughts; they happen unconsciously.

\section{References}

[1] Nida, E.A. (1952) God’s Word in Man's Language. Harper \& Brothers, New York.

[2] Sperber, D. and Wilson, D. (1986) Relevance: Communication and Cognition. Blackwell, Oxford.

[3] Gutt, E.A. (1991) Translation and Relevance: Cognition and Context. Blackwell, Oxford.

[4] Zhao, Y.C. (1999) Relevance Explanation of Translation. Modern Foreign Language, 3, 273-295.

[5] Brown, P. and Levinson, S. (1978) Universals in Language Usage: Politeness Phenomena. In: Goody, E., Ed., Questions and Politeness: Strategies in Social Interaction, Cambridge University Press, Cambridge.

[6] Brown, P. and Levinson, S. (1987) Politeness: Some Universals in Language Usage. Cambridge University Press, Cambridge.

[7] House, J. (2000) Politeness and Translation. In: Hickey, L., Ed., The Pragmatics of Translation, Multilingual Matters Ltd., Clevedon.

[8] Gutt, E.A. (2000) Translation and Relevance: Cognition and Context. St. Jerome Publishing, Manchester.

[9] Lakoff, R.T. (1990) Talking Power. Basic Books, New York.

[10] Leech, G.N. (1983) Principles of Pragmatics. Longman, London. 
[11] Thomas, J. (1995) Meaning in Interaction. Longman, London.

[12] Fraser, B. (1990) Perspectives on Politeness. Journal of Pragmatics, 14, 219-236. http://dx.doi.org/10.1016/0378-2166(90)90081-N

[13] Nwoye, O.G. (1992) Linguistic Politeness and Socio-Cultural Variations of the Notion of Face. Journal of Pragmatics, 18, 309-328. http://dx.doi.org/10.1016/0378-2166(92)90092-P

[14] Grice, P. (1975) Logic and Conversation. In: Cole, P. and Morgan, J.L., Eds., Syntax and Semantics 3: Speech Acts, Academic Press, New York, 41-58.

[15] Lakoff, R.T. (1973) The Logic of Politeness, or Minding Your P’s and Q’s. Vol. 9, Chicago Linguistic Society, Chicago, 292-305.

[16] Brown, P. (1980) How and Why Women Are More Polite. Some Evidence from a Mayan Community. In: McConnell-Ginet, S., Borker, R. and Furman, N., Eds., Women and Language in Literature and Society, Praeger, New York, 111-135.

[17] Mao, R.L. (1994) Beyond Politeness Theory: “Face” Revisited and Renewed. Journal of Pragmatics, 21, $451-486$. http://dx.doi.org/10.1016/0378-2166(94)90025-6

[18] Goffman, E. (1967) Interaction Ritual. Anchor, New York.

[19] Ide, S. (1989) Formal Forms and Discernment: Tow Neglected Aspects of Linguistic Politeness. Multilingua, 8, 223238. http://dx.doi.org/10.1515/mult.1989.8.2-3.223

[20] Fraser, B. (1978) Acquiring Social Competence in a Second Language. RELC Journal, 9, 1-21. http://dx.doi.org/10.1177/003368827800900201

[21] House, J. and Kasper, G. (1981) Polietness Markers in Engllish and German. In: Coulmas, F., Ed., Conversational Routine, Mouton, The Hague.

[22] Ide, S., Hill, B., Carners, Y.M., Ogino, T. and Kawasaki, A. (1992) The Concept of Politeness: An Empirical Study of American English and German. In: Watts, R., Ide, S. and Ehlich, K., Eds., Politeness in Language: Studies in Its History, Theory and Practice, Mouton de Gruyter, Berlin.

[23] Sperber, D. and Wilson, D. (1995) Relevance: Communication and Cognition. 2nd Edition, Blackwell, Oxford. 
Scientific Research Publishing (SCIRP) is one of the largest Open Access journal publishers. It is currently publishing more than 200 open access, online, peer-reviewed journals covering a wide range of academic disciplines. SCIRP serves the worldwide academic communities and contributes to the progress and application of science with its publication.

Other selected journals from SCIRP are listed as below. Submit your manuscript to us via either submit@scirp.org or Online Submission Portal.
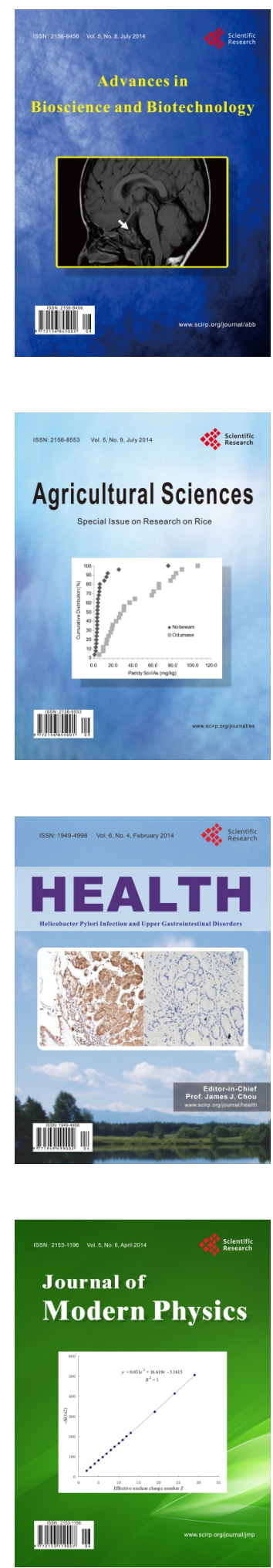
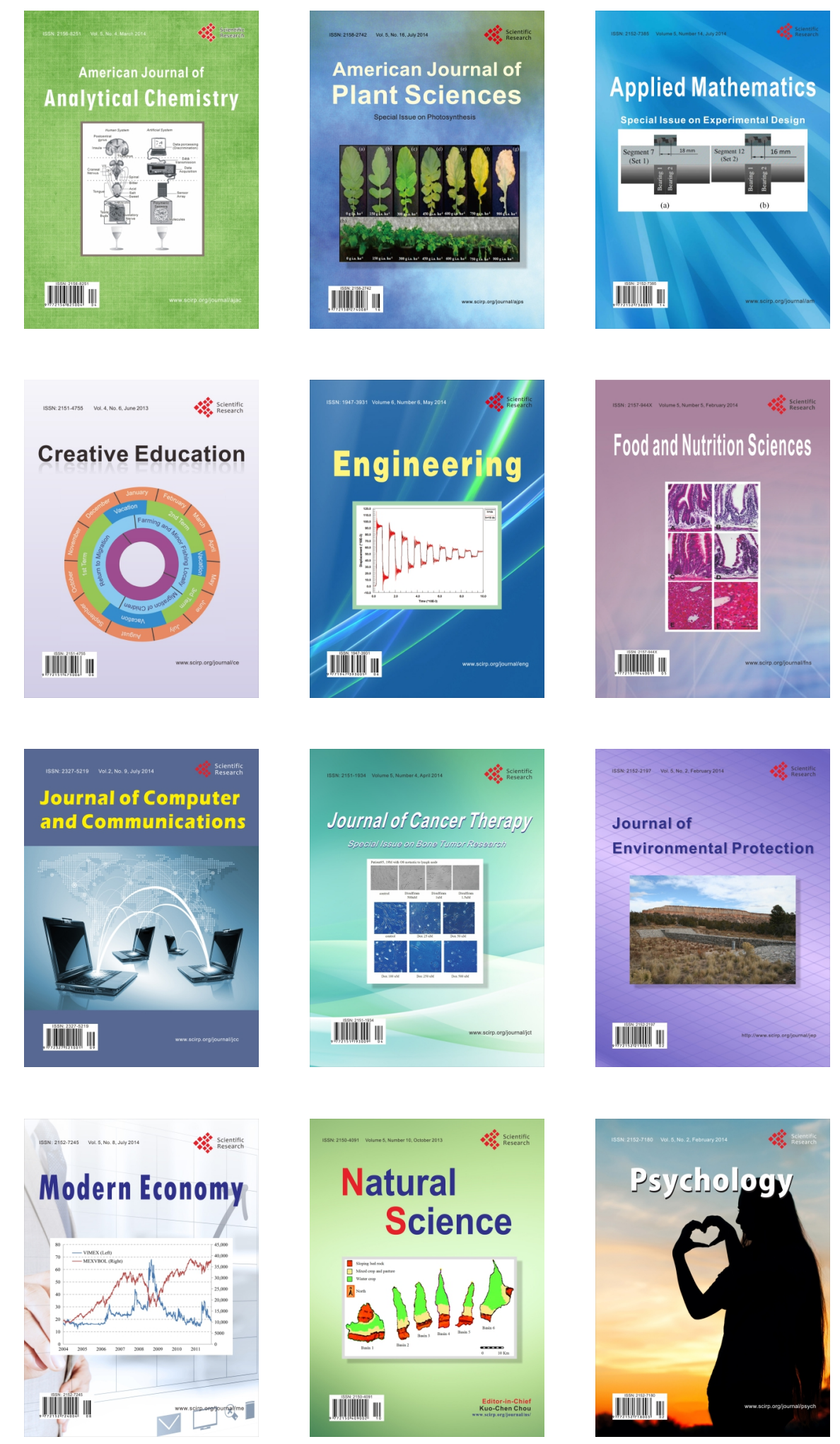